\title{
Low prevalence of APP duplications in Swedish and Finnish patients with early-onset Alzheimer's disease
}

\author{
Elin S Blom ${ }^{\star 1,3}$, Jayashree Viswanathan ${ }^{2,3}$, Lena Kilander ${ }^{1}$, Seppo Helisalmi ${ }^{2}$, \\ Hilkka Soininen ${ }^{2}$, Lars Lannfelt ${ }^{1}$, Martin Ingelsson ${ }^{1}$, Anna Glaser ${ }^{1,3}$ and Mikko Hiltunen ${ }^{2,3}$
}

${ }^{1}$ Section of Molecular Geriatrics, Department of Public Health and Caring Sciences, Uppsala University, Uppsala, Sweden; ${ }^{2}$ Department of Neuroscience and Neurology, University of Kuopio, Kuopio, Finland

Familial early-onset Alzheimer's disease with cerebral amyloid angiopathy (EOAD/CAA) was recently associated with duplications of the gene for the amyloid- $\beta$ precursor protein (APP). In this study, we have screened for duplications of $A P P$ in patients with EOAD from Sweden and Finland. Seventy-five individuals from families with EOAD and 66 individuals with EOAD without known familial inheritance were screened by quantitative PCR. On the basis of the initial results, a portion of the samples was also investigated with quantitative multiplex PCR. No duplications of $A P P$ were identified, whereby we conclude that this is not a common cause of EOAD in the Swedish and Finnish populations, at least not in our collection of families and cases.

European Journal of Human Genetics (2008) 16, 171-175; doi:10.1038/sj.ejhg.5201966; published online 28 November 2007

Keywords: early-onset Alzheimer's disease; amyloid beta precursor protein; gene dose; APP; duplication

\section{Introduction}

Genetics is one of the major risk factors for developing Alzheimer's disease (AD). Four genes are known to be involved in $\mathrm{AD}$ and mutations in three of these cause autosomal dominant early-onset Alzheimer's disease (EOAD): the amyloid- $\beta$ precursor protein (APP) on chromosome $21,{ }^{1}$ presenilin 1 (PSEN1) on chromosome $14^{2}$ and presenilin 2 (PSEN2) on chromosome $1 .^{3}$ In addition, the 84 allele of apolipoprotein E (APOE) on chromosome 19 increases the risk of developing late-onset sporadic $\mathrm{AD}$ and decreases the age at onset in a dose-dependent manner. ${ }^{4}$ Most of these genetic variants are believed to result in increased production of the amyloid- $\beta(\mathrm{A} \beta)$ peptide or a shift in the $\mathrm{A} \beta_{40} / \mathrm{A} \beta_{42}$ ratio to increase the amount of the

*Correspondence: ES Blom, Department of Public Health and Caring Sciences, Uppsala University, Rudbeck Laboratory, Dag Hammarskjölds väg 20, Uppsala 75185, Sweden.

Tel: + 46 (0)18 47150 30; Fax: + 46 (0)18 47148 08;

E-mail: elin.blom@pubcare.uu.se

${ }^{3}$ These authors have contributed equally to this work.

Received 5 July 2007; revised 10 October 2007; accepted 31 October 2007; published online 28 November 2007 more amyloidogenic peptide $\mathrm{A} \beta_{42}$. Amyloid- $\beta$ is cleaved from APP by $\gamma$-secretase whose active constituent is one of the presenilin proteins ${ }^{5}$ and $A P O E \varepsilon 4$ has been associated with increased $\mathrm{A} \beta$ deposition. ${ }^{6}$

Variability in the expression of APP can also cause AD. Individuals with Down's syndrome (DS, trisomy 21) usually develop AD pathology in early middle age due to an extra copy of the APP gene. ${ }^{7}$ Also, two research groups have recently reported that duplications of $A P P$, in the absence of trisomy 21, can cause familial EOAD with cerebral amyloid angiopathy (EOAD/CAA). ${ }^{8,9}$

In this study, we screened for APP duplications in affected subjects from Swedish and Finnish families and cases with EOAD in an effort to estimate the frequency of $A P P$ duplications in EOAD patients in these populations.

\section{Materials and methods}

Samples

The Swedish sample set consisted of 85 patients from the Memory Clinics of Uppsala Academic Hospital and Karolinska University Hospital, Huddinge. After a quality 
Table 1 Samples analyzed for APP gene dose

\begin{tabular}{lcccc}
\hline Cohort & $\begin{array}{c}\text { Total } \\
\text { samples }\end{array}$ & $\begin{array}{c}\text { Familial } \\
\text { EOAD }\end{array}$ & $\begin{array}{c}\text { Sporadic } \\
\text { EOAD }\end{array}$ & $\begin{array}{c}\text { Age at } \\
\text { onset } \pm \text { SD }\end{array}$ \\
\hline Swedish & 77 & 45 & 32 & $56.9 \pm 6.1$ \\
Finnish & 64 & 30 & 34 & $59.7 \pm 5.3$ \\
Total & 141 & 75 & 66 & $58.2 \pm 5.9$ \\
\hline
\end{tabular}

control, eight samples were removed. The remaining 77 samples with age at disease onset $\leq 65$ years ( $41-65$ years, mean $\pm \mathrm{SD}=56.9 \pm 6.1$ years; $57 \%$ women) were included in a screen for APP duplications. All patients were clinically diagnosed as possible or probable EOAD according to NINCDS-ADRDA. ${ }^{10}$ Autopsy was performed on 17 of these patients, 11 of whom had congophilic vessels. Forty-five patients had familial EOAD with at least one known firstdegree relative affected by $\mathrm{AD}$, and 32 were cases without known familial inheritance (Table 1). The Swedish sample collection included the two families with the Swedish $(\mathrm{K} 670 \mathrm{~N} / \mathrm{M} 671 \mathrm{~L})^{11}$ and Arctic (E693G) ${ }^{12}$ APP mutations.

The Finnish sample set consisted of 64 patients from eastern Finland, all examined at the Kuopio University Hospital, with age at disease onset $\leq 65$ years ( $45-65$ years, mean $\pm \mathrm{SD}=59.7 \pm 5.3 ; 72 \%$ women). All patients fulfilled clinical criteria for probable $\mathrm{AD}$ according to NINCDSADRDA. ${ }^{10}$ Thirty patients had familial EOAD where at least two affected first-degree relatives in two generations had been documented. ${ }^{13}$ The remaining 34 patients had sporadic EOAD (Table 1). All samples had been screened for mutations in APP, PSEN1 and PSEN2 without positive findings.

This study was approved by the Ethics Committees of Uppsala University and Kuopio University Hospital.

\section{Allele quantification}

Primers for APP1i (intron after exon 1), APP2ei (exon/ intron border of exon 2), APP9ei (exon/intron border of exon 9), APP16i (intron after exon 16), glycogenin 2 (GYG2) on chromosome $\mathrm{X}$ and deleted in azoospermia 4 (DAZ4) on chromosome $\mathrm{Y}$ were designed using the PrimerExpress software (Applied Biosystems, Foster City, CA, USA); sequences are available upon request. Primers from within the APP promoter, APP5e (exon 5) and APP18i (the intron after exon 18) were used in Sleegers et al. ${ }^{9}$ Primers for the control genes hemoglobin beta $(H B B)$ on chromosome 11, glyceraldehyde-3-phosphate dehydrogenase $(G A P D H)$ on chromosome 12 and ubiquitin $\mathrm{C}(U B C)$ on chromosome 12 , have previously been used in Johnson et $a l_{,}{ }^{14}$ West et $a l^{15}$ and in Sleegers et al, ${ }^{9}$ respectively.

The Swedish samples were screened for gene load by quantitative PCR (qPCR) using the SYBR green chemistry on the MyiQ Single Color Real-Time PCR Detection System (Bio-Rad, Richmond, CA, USA). The samples were amplified in a volume of $25 \mu \mathrm{l}$, containing $10 \mathrm{ng}$ of genomic DNA, $2 \times$ Power SYBR Green PCR Master Mix (Applied
Biosystems) and $200 \mathrm{~nm}$ of each primer, using the universal thermal cycling parameters (Applied Biosystems). Each plate included triplicate DNA samples from EOAD patients, a healthy control as calibrator sample and two DS patients as positive controls. Wells without template were included as negative controls. SD were calculated for the triplicates. If the SD for a triplicate was more than 0.3, the sample was rerun. The number of gene copies was determined relative to $H B B$ and normalized to the calibrator sample using the $2^{-\Delta \Delta C_{t}}$ method (Applied Biosystems).

The Finnish samples were screened for the presence of $A P P$ duplications using both $\mathrm{qPCR}$ and a quantitative multiplex PCR (qmPCR) assay. For qPCR, $25 \mathrm{ng}$ of genomic DNA was amplified in a volume of $25 \mu$ l together with $2 \times$ Power SYBR Green PCR Master Mix (Applied Biosystems) and $600 \mathrm{nM}$ of each primer (APP5e or APP16i). Each plate included DNA samples from EOAD patients, four DS patients and four healthy controls, all analyzed in duplicates. The gene dose of $A P P$ was calculated using the standard curve method (Applied Biosystems), compared to $H B B$ and normalized to the mean of the healthy controls. The qmPCR was performed in a multiplex PCR using $A P P 5 \mathrm{e}, A P P 16 \mathrm{i}$ and $H B B$ where all forward primers were labeled with the fluorescent dye FAM. The reaction mix contained $25 \mathrm{ng}$ of DNA, primers for APP5e (200 nM), $A P P 16 \mathrm{i}(100 \mathrm{~nm})$ and $H B B(200 \mathrm{nM}), 10 \times$ buffer, $10 \mathrm{~mm}$ dNTP and 2.5 U HotStarTaq polymerase enzyme (QIAGEN, Hilden, Germany). The number of cycles needed to reach the exponential phase was determined experimentally. Subsequently, $1 \mu \mathrm{l}$ fluorophore-labeled PCR product was mixed with $10 \mu \mathrm{l} \mathrm{HiDi} \mathrm{Formamide} \mathrm{and} 0.75 \mu \mathrm{l}$ GeneScan 600 LIZ Size Standard (Applied Biosystems). The PCR product was denatured at $95^{\circ} \mathrm{C}$ for $3 \mathrm{~min}$ and cooled on ice for $2 \mathrm{~min}$. Samples were analyzed through capillary electrophoresis using an ABI 3100 (Applied Biosystems) and the results were viewed using GeneMapper v.3.0 (Applied Biosystems). The peak height was used to determine gene dose of APP5e and APP16i compared to $H B B$, and all samples were normalized to the mean of the healthy controls.

\section{SNP arrays}

To verify a potential duplication of the APP gene, one sample from the Swedish cohort was run on GeneChip Human Mapping 250K Nsp Arrays (Affymetrix, Santa Clara, CA, USA) according to protocol. The Nsp array has 45 single nucleotide polymorphisms (SNPs) within APP. Results were analyzed with the GTYPE software (Affymetrix).

\section{Results}

As the qPCR method is dependent on high-quality DNA, the Swedish samples were evaluated by screening with GYG2 on chromosome X. Gene dose data were thereafter related to gender (Figure 1a). Eight samples did not 

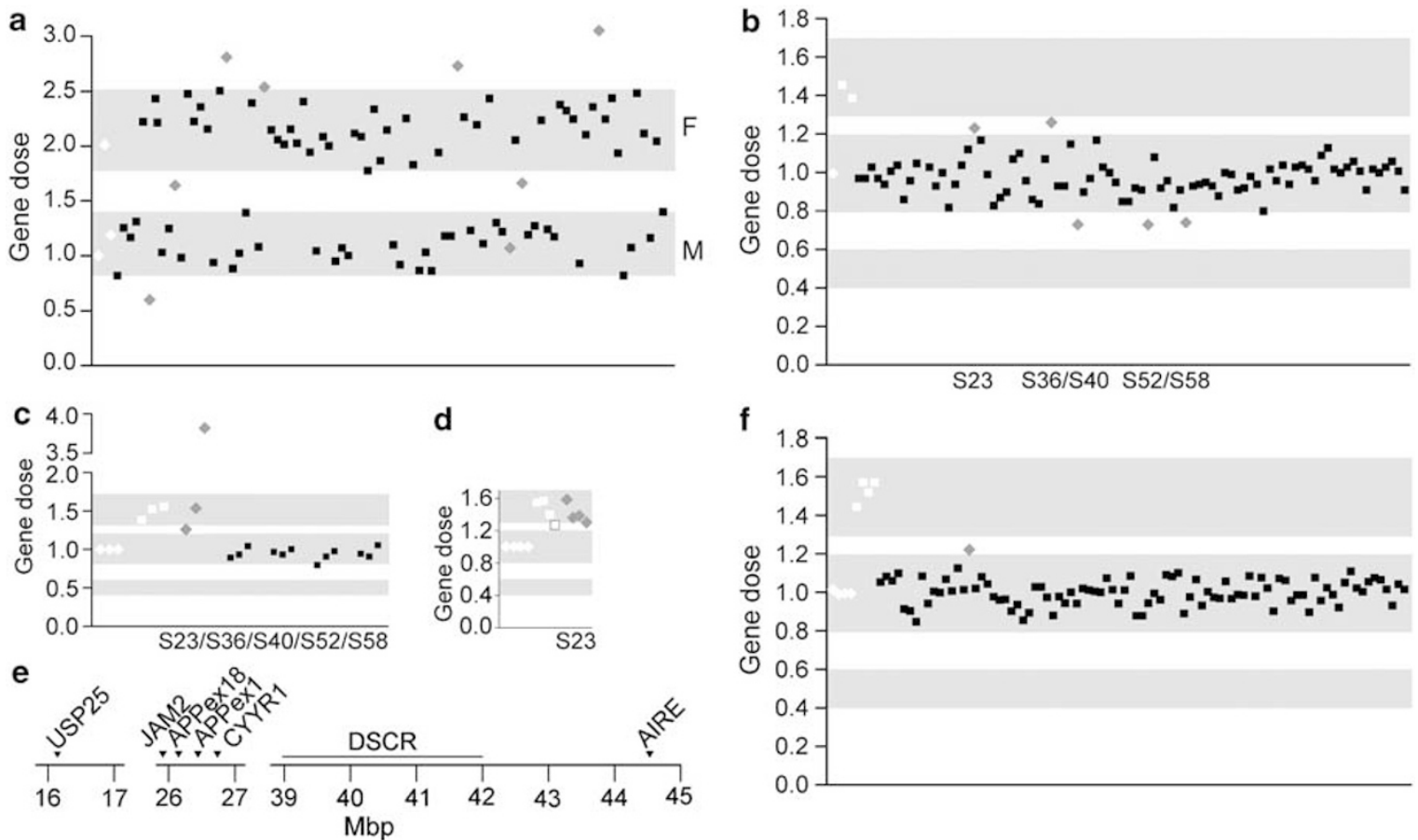

Figure 1 Gene dose analyses. (a) Quality control of the Swedish samples using GYG2 on chromosome X for correlation to gender, a value of 0.8 1.4 represents men and 1.8-2.5 represents women; (b) Analysis of APP gene dose in the Swedish cohort using primers for intron 16 of APP. Values between 0.4 and 0.6 correspond to a deletion, $0.8-1.2$ is normal gene dose and 1.3-1.7 denotes a duplication; (c) follow-up analysis of five Swedish samples; primers for the promotor, intron 9 and intron 18 of APP were used; (d) one Swedish sample in a follow-up analysis of USP25, JAM2, CYYR1 and AIRE; (e) location of the analyzed genes on chromosome 21. Down's syndrome critical region (DSCR) is located in the region of $39-42 \mathrm{Mbp} ;{ }^{16}$ (f) analysis of APP gene dose in the Finnish samples using primers for intron 16 of APP. APP gene dose in the Swedish cohort was determined through qPCR, compared to $H B B$ and normalized to the calibrator sample using the $2^{-\Delta \Delta C_{t}}$ method. All samples were run in triplicates and SD were calculated. If the SD for a triplicate was more than 0.3 , the sample was rerun. Number of gene copies in the Finnish cohort was determined through qmPCR, compared to $H B B$ and normalized to the mean of four healthy control samples. White diamonds represent healthy controls, white squares represent Down's syndrome, gray diamonds represent samples outside the specified range and black squares are samples with values within the set gene dose range.

show the expected gene dose on chromosome $\mathrm{X}$ and were therefore considered unreliable. They were excluded from further analyses after confirmation of gender with DAZ4 on chromosome Y. The remaining 77 Swedish samples were screened for APP gene dose using qPCR with primers for APP16i (Figure 1b) and APP1i or $A P P 2$ ei. Initially, five samples with values outside the normal gene dose were detected in the Swedish cohort. Four of the samples were considered normal based on further analysis with additional primers within the APP gene (the promotor, APP9ei and APP18i) (Figure 1c). One sample still appeared duplicated and the extent of the increased gene dose region was analyzed with two genes flanking APP, JAM2 and CYYR1. Two genes in more distant regions of chromosome 21, USP25 and AIRE, were also analyzed. These genes were compared to $H B B$ (Figure 1d), indicating duplication of one or several regions spanning $>28 \mathrm{Mbp}$ on chromosome 21 (Figure 1e). This region also spanned the Down's syndrome critical region (DSCR), the smallest duplicated region of chromosome 21 identified in patients with partial trisomy $21,{ }^{16}$ but there were no indications that this patient had DS. To investigate whether this ambiguous duplication could simply be due to a deletion of the control gene, all four genes and APP16i were compared to $G A P D H$ and $U B C$. This did not alter the results. However, the sample demonstrated no duplications of the APP locus when run on a GeneChip 250K SNP array or analyzed using qmPCR.

The Finnish samples were screened for APP duplications using APP16i and APP5e in both qPCR and qmPCR. Seven samples demonstrating increased gene dose in $\mathrm{QPCR}$ were re-extracted from peripheral blood lymphocytes and qPCR analysis was repeated. After this, all samples demonstrated normal values. One sample demonstrated a slightly elevated gene dose in qmPCR for both APP16i (Figure 1f) and APP5e (1.20/1.22), but gene dose was normal (1.02/ 1.11) in GPCR analysis.

\section{Discussion}

This screen for APP duplication included a total of 141 EOAD samples from Sweden and Finland. However, no 
duplication of the APP locus could be identified. In two recent studies using French $^{8}$ and Dutch ${ }^{9}$ samples, the frequencies of $A P P$ duplication were calculated to 8 and $2.7 \%$ of familial EOAD, respectively. If these frequencies were valid also for the Swedish and Finnish populations, we would have expected to find between two and six cases of APP duplication in our familiar cases. However, the occurrence of $A P P$ duplication seems to be more infrequent in the Swedish and Finnish populations.

One sample was concluded to be a false positive finding, as the putative duplication was very large and spanned DSCR, which is not consistent with a non-DS diagnosis. ${ }^{16}$ There is a hypothetical possibility that this is not an uninterrupted duplication on one chromosome, but rather two independent duplications on separate chromosomes where DSCR is not included. However, this sample did not show any signs of duplication when tested with two other methods, qmPCR and GeneChip SNP arrays.

Neither qPCR nor qmPCR analyses demonstrated evidence of APP gene duplication among the Finnish EOAD patients. Although qmPCR was less variable than qPCR, there were no indications of false negative results using either method, as DS samples consistently demonstrated duplication of chromosome 21. We therefore consider both methods reliable for gene dose screening.

French $^{8}$ and Dutch ${ }^{9}$ studies have demonstrated APP duplication ranging from minimally 0.29 up to $6.37 \mathrm{Mb}$, and containing either only the APP gene ${ }^{9}$ or up to 12 genes. ${ }^{8}$ All these duplications were presented with EOAD/ CAA. Also, a report on an APP duplication in a Finnish family ${ }^{17}$ was associated with progressive cognitive decline with coexisting intracerebral hemorrhages, but where the affected family members displayed a cognitive profile somewhat different from that typically seen in AD. Moreover, DS subjects with three copies of chromosome 21, and thereby of $A P P$, usually develop $\mathrm{AD}$ although intracerebral hemorrhages have only occasionally been reported. ${ }^{18}$ These differences in disease presentation could be related to which and how many additional genes are within the duplicated region. Nonetheless, the central role of APP duplications for AD development is emphasized further by a rare case of DS caused by partial trisomy 21 distal to the $A P P$ gene. This individual did not show any signs of AD, neither neuropsychological nor neuropathological, at her death at age 78 years. ${ }^{19}$

In conclusion, we screened a collection of patients from Sweden and Finland with $\mathrm{AD}$ and onset at or before 65 years of age, but found no cases of APP duplications. We therefore conclude that duplication of the APP gene is not a common cause of EOAD in Swedish and Finnish populations.

\section{Acknowledgements}

We express our appreciation to all the families who participated in this study and to all the people involved in the collection of the samples, including Dr Marie-Louise Bondeson at the Department of Genetics and Pathology, Uppsala University, Sweden, for the Swedish Down's syndrome samples. We also thank Professor Christine Van Broeckhoven at Department of Molecular Genetics, University of Antwerp, Belgium, for providing us with primer sequences for the promoter of APP, APP5e and APP18i. This work was supported by The Swedish Research Council, The Swedish Alzheimer foundation, APOPIS (Contract no. LSHM-CT-2003-503330), Gun and Bertil Stohnes foundation, the Dementia foundation, EVO Grant 5772708 from Kuopio University Hospital, the Marie Curie Early Researcher Program, BiND, University of Kuopio (JV) and by the EU regional funds project no. 86428 .

\section{References}

1 Kang J, Lemaire HG, Unterbeck A et al: The precursor of Alzheimer's disease amyloid A4 protein resembles a cell-surface receptor. Nature 1987; 325: 733-736.

2 Sherrington R, Rogaev EI, Liang Y et al: Cloning of a gene bearing missense mutations in early-onset familial Alzheimer's disease. Nature 1995; 375: 754-760.

3 Levy-Lahad E, Wasco W, Poorkaj P et al: Candidate gene for the chromosome 1 familial Alzheimer's disease locus. Science 1995; 269: 973-977.

4 Corder EH, Saunders AM, Strittmatter WJ et al: Gene dose of apolipoprotein E type 4 allele and the risk of Alzheimer's disease in late onset families. Science 1993; 261: 921-923.

5 Edbauer D, Winkler E, Regula JT, Pesold B, Steiner H, Haass C: Reconstitution of gamma-secretase activity. Nat Cell Biol 2003; 5: 486-488.

6 Holtzman DM, Bales KR, Tenkova T et al: Apolipoprotein E isoform-dependent amyloid deposition and neuritic degeneration in a mouse model of Alzheimer's disease. Proc Natl Acad Sci USA 2000; 97: 2892-2897.

7 Olson MI, Shaw CM: Presenile dementia and Alzheimer's disease in mongolism. Brain 1969; 92: 147-156.

8 Rovelet-Lecrux A, Hannequin D, Raux G et al: APP locus duplication causes autosomal dominant early-onset Alzheimer disease with cerebral amyloid angiopathy. Nat Genet 2006; 38 : 24-26.

9 Sleegers K, Brouwers N, Gijselinck I et al: APP duplication is sufficient to cause early onset Alzheimer's dementia with cerebral amyloid angiopathy. Brain 2006; 129: 2977-2983.

10 McKhann G, Drachman D, Folstein M, Katzman R, Price D, Stadlan EM: Clinical diagnosis of Alzheimer's disease: report of the NINCDS-ADRDA Work Group under the auspices of Department of Health and Human Services Task Force on Alzheimer's Disease. Neurology 1984; 34: 939-944.

11 Mullan M, Crawford F, Axelman $\mathrm{K}$ et al: A pathogenic mutation for probable Alzheimer's disease in the APP gene at the N-terminus of beta-amyloid. Nat Genet 1992; 1: $345-347$.

12 Nilsberth C, Westlind-Danielsson A, Eckman CB et al: The 'Arctic' APP mutation (E693G) causes Alzheimer's disease by enhanced Abeta protofibril formation. Nat Neurosci 2001; 4: $887-893$.

13 Lehtovirta M, Soininen $\mathrm{H}$, Helisalmi S et al: Clinical and neuropsychological characteristics in familial and sporadic Alzheimer's disease: relation to apolipoprotein E polymorphism. Neurology 1996; 46: 413-419.

14 Johnson J, Ostojic J, Lannfelt L et al: No evidence for tau duplications in frontal temporal dementia families showing genetic linkage to the tau locus in which tau mutations have not been found. Neurosci Lett 2004; 363: 99-101.

15 West AB, Kapatos G, O'Farrell C et al: N-myc regulates parkin expression. J Biol Chem 2004; 279: 28896-28902.

16 Sinet PM, Theophile D, Rahmani Z et al: Mapping of the Down syndrome phenotype on chromosome 21 
at the molecular level. Biomed Pharmacother 1994; 48: $247-252$.

17 Rovelet-Lecrux A, Frebourg T, Tuominen H, Majamaa K, Campion D, Remes AM: APP locus duplication in a Finnish family with dementia and intracerebral haemorrhage. I Neurol Neurosurg Psychiatry 2007; 78: 1158-1159.
18 Cabrejo L, Guyant-Marechal L, Laquerriere A et al: Phenotype associated with APP duplication in five families. Brain 2006; 129: $2966-2976$.

19 Prasher VP, Farrer MJ, Kessling AM et al: Molecular mapping of Alzheimer-type dementia in Down's syndrome. Ann Neurol 1998; 43: $380-383$. 